\section{Kidney \\ Blood Pressure Research}

\title{
Implementing Assisted Peritoneal Dialysis in Renal Care: a Chinese-German Perspective
}

\author{
Wolfgang Pommera,b Xiaoyan Su ${ }^{c}$ Mengbi Zhang ${ }^{c}$ Fanna Liu ${ }^{a} \quad$ Lianghong Yin $^{a}$ \\ aDepartment of Nephrology, The First Affiliated Hospital of Jinan University, Guangzhou, China, \\ ${ }^{b}$ Kuratorium für Dialyse und Nierentransplantation, Neu-Isenburg, Germany, 'Nephropathy \\ Department, Tungwah Hospital of Sun Yat-Sen University, Dongguan, China
}

\section{Key Words}

Home dialysis • Assisted peritoneal dialysis • Elderly • Implementation process

\begin{abstract}
Assisted PD (assPD) is an option of home dialysis treatment for dependent end-stage renal patients and worldwide applied in different countries since more than 40 years. China and Germany shares similar trends in demographic development with a growing proportion of elderly referred to dialysis treatment. So far number of patients treated by assPD is low in both countries. We analyze experiences in the implementation process, barriers, and benefits of ass PD in the aging population to provide a model for sustainable home dialysis treatment with PD in both countries. Differences and similarities of different factors (industrial, patient and facility based) which affect utilization of assPD are discussed. AssPD should be promoted in China and Germany to realize the benefits of home dialysis for the aging population by providing a structured model of implementation and quality assurance.
\end{abstract}

(C) 2018 The Author(s)

Published by S. Karger AG, Basel

\section{Introduction}

Worldwide renal replacement therapy (RRT) is increasing in the last decades [1]. This development is significantly driven by raising awareness of chronic kidney disease (CKD), growing economic prosperity which make RRT affordable in many countries, and increase of life time in these populations [2]. Peritoneal dialysis (PD) compared to hemodialysis is a cost-effective treatment with similar or better outcome in many countries but utilization is different with increasing populations in China, Thailand, and US and a proportional decrease in Europe and Japan [3]. 


\section{Kidney Blood Pressure Research}

Home-care assistance for dialysis treatment (as in PD) enables clients incapacitated in whole or part to live at home often with the effect of preventing, delaying or substituting long-term or acute care alternatives [4]. Assisted PD (assPD) in this context means supporting people unable to perform their own PD, with trained staff (or formerly with family members) providing assistance with all or part of the dialysis procedure. Thus, assPD is an alternative to in-center hemodialysis which enables patients to stay at home, avoid inflexible dialysis schedules, and stressful transfers between home and renal facilities [5]. This is most relevant to the growing number of elder people with renal failure and additional co-morbid conditions who also need support in activities of daily life and in part specialized nursing care. Patients preferred home dialysis over facility-based care when increasing nursing support is available and wellbeing and flexibility are expected [6].

China and Germany are sharing similiar trends in demography (Table 1). In China average life time has changed in 1960 to 2017 from medium age of 43.5 to 76.7 years with significant differences between rural and urban areas along with the economic level [7-10]. In Germany, average life expectancy in the same timeframe has raised from 69.2 to 81.1 years [11]. In 2060, life expectancy will reach in Germany 88.8 years in women and 84.4 in men [11] In China, life expectancy will reach 79 years in 2030 [8]. While age is the most relevant risk factor of CKD [12] a sharp increase of the need for RRT is expected. Aging itself is heterogeneous ranging from fit to frail in the same age group. Differences in outcome of renal replacement therapy in the elderly may reflect this situation [13].

Public health care in China is changing from resources distributed primarily in hospitals to improving primary and ambulatory care, and general health status [14]. With focus on the growing elder population payments for chronic disease are increasing, reaching more than $50 \%$ of out-of-pocket costs particularly in rural areas [14]. This situation is completely different to the so-called Bismarck health care system in Germany which covers health care costs for chronic diseases, additional long-term services and supports if needed. Allocation of human resources (physicians and nurses) is a principal problem [15] and is critical in both countries. In Germany, shortage of renal physicians and nurses for hospital and outpatient care raises concerns to handle renal patients appropriately in the long-term. Nursing shortage along with growing population and the need of advanced care is also a trend in China which demands improvement in nursing training and education [16]. These and other conditions may impair penetration and utilization of assPD as recently decribed for the German situation $[3,17,18]$ (Table 2, Fig. 1).

Updated information on assPD is lacking. A first report of assPD in China was published 2012 [19]. In Germany, a systematic review focusing on reimbursement and allocation was published recently [20]. The aim of this paper is to combine experiences from working nephrologists in China and Germany to promote assPD and overcome the obviously few utilization of this treatment modality. dialysis modality. See references ${ }^{1)}[11],{ }^{2)}[47],{ }^{3)}[45],{ }^{4)}[17],{ }^{5}[46]$, 6)

\begin{tabular}{|c|c|c|}
\hline Demographic features & China & Germany \\
\hline \multicolumn{3}{|l|}{ Population (2017) } \\
\hline Total (Mio) & 1390.1 & 82.4 \\
\hline Younger age $(\%)$ & $\left.5.9^{5}\right)$ (age $>60-65$ ) & $11.0^{1)}($ age $>60-69)$ \\
\hline Older age $(\%)$ & $11.45)($ age $>65)$ & $15.3^{1)}($ age $>70)$ \\
\hline \multicolumn{3}{|l|}{ Population changes $(2060)$} \\
\hline Total (Mio) & $1091.0^{6)}$ & $76.5^{2)}$ \\
\hline Age $>65(\%)$ & $38.2^{6}$ & $31.5^{2)}$ \\
\hline \multicolumn{3}{|l|}{ Prevalence of dialysis therapy } \\
\hline Total (N per Mio population) & $375^{7)}$ & $1.147^{3)}$ \\
\hline Age in years (mean / median) male & $\mathrm{N} / \mathrm{A}$ & $66,4 / 71,00^{3)}$ \\
\hline Age in years (mean /median) female & N/A & $67,03 / 72,00^{3)}$ \\
\hline Hemodialysis & $85.8 \%{ }^{7)}$ & $93,3 \%{ }^{3}$ \\
\hline Peritoneal dialysis & $14.2 \%{ }^{7)}$ & $5,95 \% 3)$ \\
\hline \multicolumn{3}{|l|}{ Medium age of pts starting RRT } \\
\hline Hemodialysis (male/female) & $\mathrm{N} / \mathrm{A}$ & $71,00 / 73,00^{3}$ \\
\hline Peritoneal dialysis (male/female) & $\mathrm{N} / \mathrm{A}$ & $62,50 / 57,00^{3}$ \\
\hline Dialysis facilities $(\mathrm{N})$ & $51897)$ & $742^{3)}$ \\
\hline Facilities providing assisted home dialysis $(\mathrm{N})$ & $1100^{7)}$ & $146^{4)}$ \\
\hline
\end{tabular}




\section{Kidney \\ Blood Pressure Research}

Table 2. Factors which influence utilization of assisted peritoneal dialysis

\begin{tabular}{|c|c|c|}
\hline Factors & China & Germany \\
\hline \multicolumn{3}{|l|}{ Industrial supplies } \\
\hline PD Cycler & available & available \\
\hline Electrical power & available & available \\
\hline Water quality & high & high \\
\hline Modern PD solutions & treatment standard & treatment standard \\
\hline \multicolumn{3}{|l|}{ Facility aspects } \\
\hline Bias / attitudes & Mostly unbiased & Mostly unbiased according home treatment \\
\hline Prevalence / Experiences & Vary widely among regions & Varying \\
\hline Nurse Training & Once a year & On demand \\
\hline Quality assurance & Legally regulated and demanded & Legally regulated and demanded \\
\hline \multicolumn{3}{|l|}{ Health-care system } \\
\hline Payment & $\$ 14,380$ every year & $\$ 46,000-63,250$ \\
\hline Reimbursement & $70 \%$ by National Social Medical Insurance & Completely by medical insurance \\
\hline Availability of medical professionals & Restricted, shortness of medical staff & Restricted, shortness of medical staff \\
\hline \multicolumn{3}{|l|}{ Patient factors } \\
\hline Decision making & Follow himself or family members' advices & $\begin{array}{l}\text { Highly appreciated, empowered by legal } \\
\text { advices }\end{array}$ \\
\hline Acceptance of professional care & Accepted & Very well accepted \\
\hline Cultural attitudes & Mostly focused on family traditions & $\begin{array}{l}\text { Highly variable, less related to family } \\
\text { traditions, mostly focused on independence } \\
\text { and self-determination }\end{array}$ \\
\hline
\end{tabular}

\section{Models of implementing assisted PD into routine renal care}

Implementation of assPD in renal care needs a multidisciplinary team approach involving all members of the renal team, the patient itself, his/her family, and community care-givers (Fig. 2). With regard to the experiences of the "Network of Assisted Dialysis" created since 2016 [20] and working in the region of Berlin (Germany) which give support to an increasing number of facilities from outside, a multiple step procedure was created to insure timely application of assPD, i.e.:

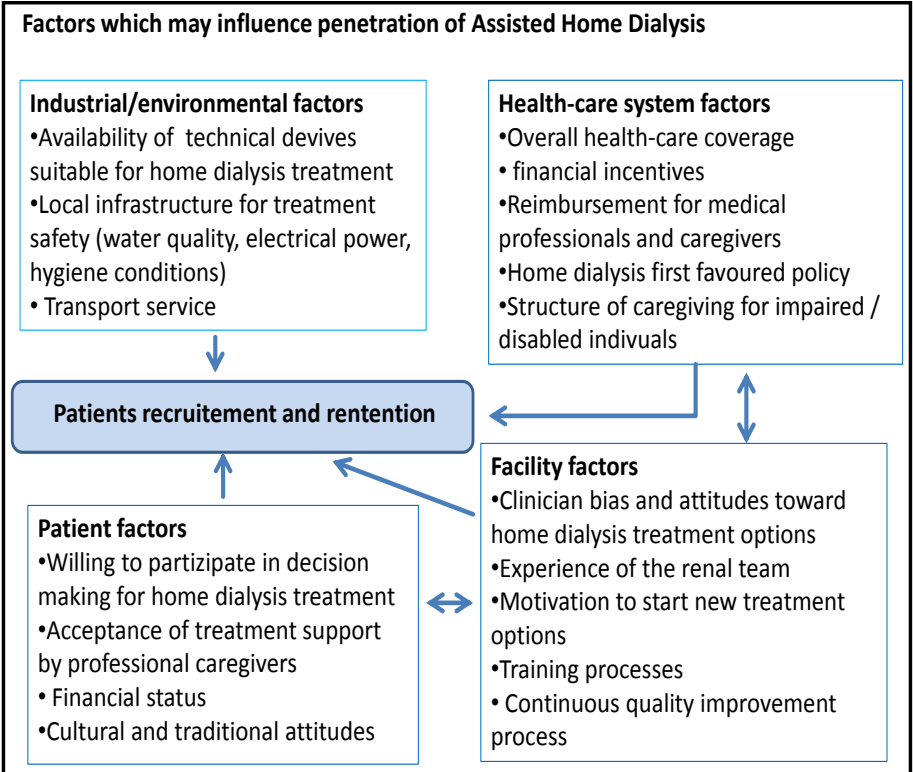

Fig. 1. Factors which may influence penetration of assisted home dialysis [adapted from 3].

\section{Initiation}

Suitable individuals with stage 4 or 5 chronic kidney disease were involved in the option of home dialysis, preferentially PD, by the renal team describing the different forms of renal replacement therapy including the strategy of conservative management if appropriate in patients with highly co-morbid conditions. Crash-landers in hospitals are explained by renal physicians if long-term renal placement therapy seems mandatory. 


\section{Kidney Blood Pressure Research}

\section{Coordination}

A central coordinator provides assistance to renal facilities and hospital units to find local care-givers who are able and willing to assist the individual patient at home. Before assPD can be established, designed locally based care-givers consistent in certified nonrenal nurses have to apply for re-imbursement of assPD care in each individual case. Reimbursement by health care insurances includes fees for assPD as well as payments for additional needed care to establish adequate support of activities of daily living and specified nursing care (i.e. medication support, blood testing, hypertension control etc.).

\section{Determination of treatment and responsibilities}

Individual renal physicians from local facilities are responsible for determination of treatment mode (CAPD or APD), treatment parameters (dialysis solutions, dwell time, fluid exchanges), and dialysis quality along with quality assurance and management of complications. PD assistance by nursing staff includes preparation of cyclers and fluid bags, connection and disconnection, exit-site care, and routinely weight and blood pressure control. These procedures can be taken in full or in part according to the patient's conditions and availability of different assisting persons.

\section{Training of professional care-givers}

Because of shortness of qualified renal staff which exclusively serves in renal facilities education and training in non-renal certified nursing staff is obligatory. A 16-hour curriculum including blended-learning, educational sessions, and bed-side teaching was designed to receive a qualification as "Certified Assistant of Peritoneal Dialysis". Re-certification after one year is mandatory to maintain qualification. Standardized training and materials are prepared by qualified nurses and physicians to insure equality of teaching process and quality. Bed-side teaching is provided by the local renal facility to which the individual patient is affiliated. Thus, specific measurements of patient's management and emergency procedures according to the individual center practice are trained.

China has implemented assPD in 2012 [20]. In a so far singular report assistance was provided by family members or by a home assistant compensated by the employer. Training was performed in the dialysis clinic and lasted 3-5 days or 5-7 sessions (1-2 hours per session) including bag exchange procedures, exit-site care, dietary restrictions, and management of non-infection catheter problems.

In China, assPD is in the early stages of development and mainly completed by family members, due to restrictions on the sources of reimbursement for medical insurance [21]. There is a special model called mutual aid mode, the assistance was provided by young PD patients, who experience strict training, examination and regular assessment [22]. Thus, the elderly paid to the young PD patients to get assistance. Medical staff manage patients by telephone or home visits every month. The social function grade of young PD patients is level 3 or 4 [23]. At level 3, PD patients, during working age but do not have a job, be able to

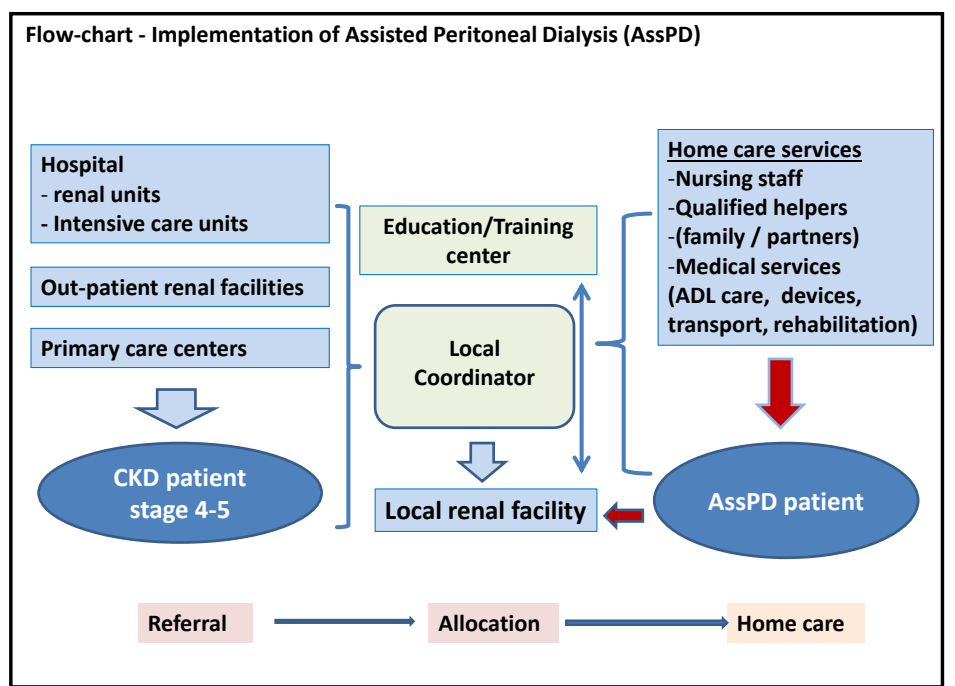

Fig. 2. Flow-chart - Implementation of assisted peritoneal dialysis. 


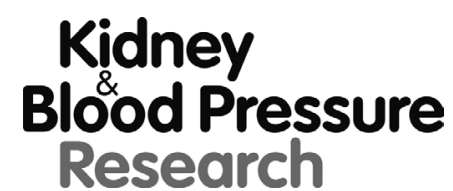

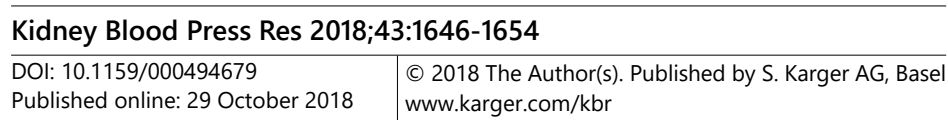

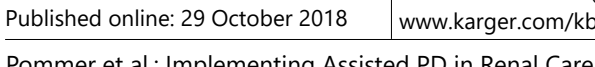

self-care and undertake at least one social participation activity. At level 4, PD patients are full-time or part-time employees, who can take care of themselves and undertake at least one social participation activity. Young PD patients must pass PD training assessment in hospital with the full score every 3 months $[19,24]$. They can work in a hospital to help the hospitalized elder PD patients, visit patients who require assPD at their homes at regular intervals.

Shared-decision making and quality assurance processing are key items for highquality care which enables patients to benefit from advantages of assPD and home-based care. Benefits are not only restricted to the advantages of PD itself, but also comprise an integrating care process, including support in ADL, treatment to improve health conditions (i.e. rehabilitation by exercising and occupational therapy), and medical therapy. Home care treatment options of assPD can be established in different settings: support in family home as well as in senior or nursing homes. The increasing need of nursing home care for the elderly in the changing process of traditional family values and capability of family members to support impaired family members emphasizes the meaning of new options in daily renal care. Thus, assPD today is a meaningful option in renal replacement therapy which meets demands derived from social demographics and the change of individual preferences in the aging population in both countries.

\section{Barriers to realize assisted PD}

Beliefs and attitudes of the physicians and staff significantly influence the implementation of home dialysis $[17,25]$. Although home dialysis is believed to be superior to conventional hemodialysis worldwide numbers are low. While PD is no longer qualified as second class treatment and improvements have made to overcome therapy related complications [26] trends in the utilization of PD worldwide are inconsistent [3]. PD population in China is increasingly growing since more than one decade [3]. But trends in Europe elucidate a turndown or stagnation in PD numbers. Since many years assPD is provided in different countries as France, Denmark, Brazil, Canada, South America, and China [27]. Although in Germany awareness of this treatment option is high number of referred patients to date are low [17]. Most of the barriers to implement assPD derive from nurse and financial shortcomings as well as lack of team motivation, funding, and reimbursement $[17,25]$.

To overcome barriers - from the view of patients and physicians - a non-biased information policy is needed and should be timely realized in the course of CKD [27-29]. Structured educational programmes are advised and resulted in increasing use of home dialysis $[29,30]$. Financial disadvantages in patients by spending higher rates of out-ofpocket costs may be a considerable problem in countries with restricted health care funding. Finally, cultural aspects as the changing value of traditional family support for impaired family members may influence treatment modality decisions.

In China, the cultural tradition encourages family members to help impaired family members. Family support shows independent benefits for outcomes in chronic conditions and decreasing the cost burden [19]. But now great changes have taken place and the number of empty-nest elderly, who do not live with their children or do not have children, is on the rise, particularly in some rural areas. This occurrence is closely related to economic prosperity and one-child policy. With the accelerated process of urbanization and the flow of rural surplus labor to big cities, some farmers have established their careers in big cities and become urban dwellers, while their parents are left behind in rural homes [31, 32]. And the one-child policy makes many families' structured as 4-2-1 as the first generation of only children has reached their marrying age. A young married couple has to take care of two sets of parents without help from siblings [31]. For such PD empty-nest elderly, implement assPD by trained home-care nurses seem is an attractive option. However, in China awareness of assPD treatment option is not widely accepted and there are not enough trained home-care 


\section{Kidney Blood Pressure Research}

nurses [33, 34]. Furthermore, in some rural areas, empty-nest families are less able to afford the cost of professional nursing staff if lack of reimbursement schemes and government policy [35]. In addition, increasing longevity and ageing populations mean demand for trained professional care-givers is likely to rise sharply. Professional nursing shortage and inadequate infrastructure in nursing home make it hard to meet demand [36].

\section{Financial aspects}

Type and intensity of assistance remain the most important factors influencing total costs of assPD. Reimbursement for similar services varies widely in European countries [37]. AssPD in frail Dutch patients has been defined as cost-effective alternative to standard hemodialysis care [38]. In Germany, cost-calculations of assPD are suggested to save almost $\$ 15,000$ yearly per patient mainly by avoiding costly transport services to renal facilities [17]. But, cost-effectiveness of assPD compared to in-center (hemo-) dialysis is finally undefined and biased by different mode of calculations and costs included [review by 27]. Nevertheless, in the lack of economical implications level of treatment satisfaction may favour patients' preferences in assPD modality choice [39].

\section{Options, advantages and future of assisted PD}

AssPD is proven to be a feasible option for - mostly elderly - dependent patients. Data from more than 40 years experiences in France [review by 26] and long-term single center results indicated that survival of patients and technical survival in assPD is similar to nonassisted PD patients $[18,40]$.

Hospitalization rates in assPD compared to non-helped PD depends on co-morbidity conditions. The proportion of non-dialysis related reasons of hospitalization are higher than PD related causes (peritonitis, exit-site infection) [40]. Method specific complications seems to be similar in assPD and non-assisted PD $[27,40]$. Switch to hemodialysis in assPD is lower than in self-care PD [40]. Nurse-assisted PD compared to family-assisted PD is associated with a lower rate of peritoneal infection [27].

Quality of life, physical functioning, and treatment satisfaction are key values of RRT in the elderly. Quality of life and physical function in older patients on assPD are equal compared to similar hemodialysis patients, but treatment satisfaction in assPD is higher [39]. This is supported by quality of life assessment in older patients where PD patients experienced less illness and treatment intrusion compared to those on hemodialysis [41].

Finally, the experience of patients and care-givers significantly influence outcomes in assistant treatment modalities. The experience of other patients is important in treatment choice and considering home dialysis as a treatment option [42, 43]. From these aspects timely offering of treatment options (including conservative care), structured pre-dialysis education, and reassurance from peers is essential for improving utilization of home dialysis. Furthermore, professional assistance in assPD by qualified nursing staff, as preferred in Germany and is realized for many decades in France, overcome hazardous family interaction and loose of sustaining relationship in families where family members need sustainable care. Professional nursing staff assistance and sufficient reimbursement beyond using family resources to establish long-term assistance in $\mathrm{PD}$, is an appropriate approach to overcome socio-demographic limitations of single-child families, divorced relationships, moving from parents' home, and need of flexibility in job careers. 


\section{Kidney Blood Pressure Research}

\section{Summary and conclusion}

Home dialysis

is more than a treatment: it is a system where medical treatment is matched to patients' needs, family background, cultural demands, and requirements of the health care system. AssPD is a feasible - but so far underused treatment option of RRT in countries

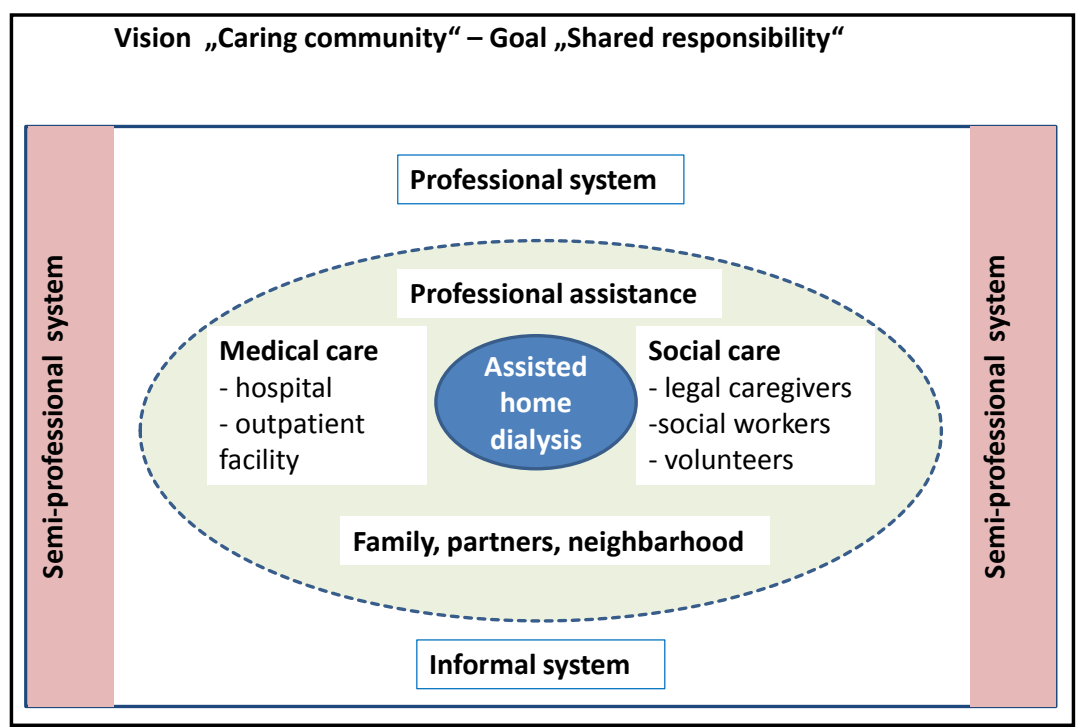

Fig. 3. A model of caring community. with a growing elderly population. In both countries, China and Germany, in-center dialysis is dominated the spectrum of RRT. AssPD is not inferior to self-care PD in several outcomes. AssPD provides an unique option to combine lower treatment costs of PD with the needs of home services medical and non-medical - in the dependent dialysis population in which home treatment is primarily not suggested, neither by patients, their families nor by renal physicians. This focus requires a change from current dialysis treatment of facility based to home based treatment. A timely pre-dialysis education, implementation of a structured model for care, education and training of helping staff, and constantly monitoring of quality parameters is necessary. To overcome barriers of assPD utilization motivation of renal professionals is mandatory. Reimbursement of professional assistance including training and education remains a problem which has to be solved in both countries. Finally, activities of the implementation of assPD is part of a concept of a "caring community" which shares responsibility of social care with professional and semi-professional caregivers in a local community network (Fig. 3).

\section{Disclosure Statement}

The authors declare they have no conflicts of interest.

\section{References}

1 National Kidney Foundation: Global Facts: About Kidney Disease. URL: https://www.kidney.org/ kidneydisease/global-facts-about-kidney-disease.

2 Bello AK, Levin A, Tonelli M, Okpechi IG, Freehally J, Harris D, Jindal K, Salaka BL, Rateb A, Osman MA, Qarni B, Saad S, Lunney M, Wiebe N, Ye F, Johnson DW: Global kidney health atlas: A report by the International Society of Nephrology on the current state of organization and structures for kidney care across the globe. International Society of Nephrology, Brussels, Belgium, 2017. URL: https://www.theisn.org/images/ISN_ advocacy/GKHAtlas_Linked_Compressed1.pdf.

3 Li PKT, Chow KM, van de Luijtgaarden MWM, Johnson DW, Jager KJ, Mehrotra R, Naicker S, Pecoits-Filho $\mathrm{R}, \mathrm{Yu} \mathrm{XQ}$, Lamiere N: Changes of the worldwide epidemiology of peritoneal dialysis. Nat Rev Nephrol 2017;13:90-104. 


\section{Kidney \\ Blood Pressure Research}

-4 Aydede SK, Komenda P, Djurdjev O, Levin A: Chronic kidney disease and support provided by home care services: a systematic review. BMC Nephrology 2014;15:118.

5 Brown EA, Wilkie M: Assisted peritoneal dialysis as an alternative to in-center hemodialysis. Clin J Am Soc Nephrol 2016;11:1522-1524.

6 Walker RC, Morton RL, Palmer SC, Marshall MR, Tong A, Howard K: A discrete choice study of patient preferences for dialysis modalities. Clin J Am Soc Nephrol 2018;13:100-108.

7 Statistical Bulletin on the Development of Health Care in China (2017). URL: http://www.nhfpc.gov.cn/ guihuaxxs/s10743/201806/44e3cdfe11fa4c7f928c879d435b6a18.shtml.

8 "Healthy China 2030" Planning Outline (2016). URL: http://www.nhfpc.gov.cn/guihuaxxs/ s3586s/201610/21d120c917284007ad9c7aa8e9634bb4.shtml.

9 National Population Development Plan (2016-2030) (2017). URL: http://www.nhfpc.gov.cn/bgt/ gwywj2/201701/a6dd45cf1660432c91a9ada5e758a4a2.shtml.

10 He CQ: China Modernization Report 2017: Health Modernization Research. Peking University Press, 2017.

11 Statista. Das Statistik-Portal: Entwicklung der Lebenserwartung bei Geburt in Deutschland nach Geschlecht in den Jahren von 1950 bis 2060 (in Jahren). URL: https://de.statista.com/statistik/daten/studie/273406/ umfrage/entwicklung-der-lebenserwartung-bei-geburt--in-deutschland-nach-geschlecht/.

-12 Mills KT, Xu Y, Zhang W, Bundy JD, Chen CS, Kelly TN, Chen J, He J: A systematic analysis of world-wide population based data of the global burden of chronic kidney disease in 2010. Kidney Int 2015;88:950-957.

13 Swidler MA: Geriatric renal palliative care. J Gerontol A Biol Sci Med Sci 2012;67:1400-1409.

14 Deng F, Ly JH, Wang HL, Gao JM, Zhou ZL: Expanding public health in China: an empirical analysis of healthcare inputs and outputs. Public Health 2017;142:73-84.

15 Kabene SM, Orchard C, Howard JM, Soriano MA, Leduc R: The importance of human resources management in health care: a global context. Hum Resour Health 2006;4:20.

$>16$ Wang CC, Whitehead L, Bayes S: Nursing education in China: Meeting the global demand for quality healthcare. Int J Nurs Sci 2016;3:131-136.

17 Pommer W, Wagner S, Mueller D, Thumfart J: Attitudes of nephrologists towards assisted home dialysis in Germany. Clin Kidney J 2018:11:400-405.

-18 Querido S, Branco PQ, Costa E, Pereira S, Gaspar MA, Barata JD: Results in assisted peritoneal dialysis: A ten year experience. Int J Nephrol 2015;2015:712539.

19 Xu R, Zhuo M, Yang Z, Dong J: Experiences with assisted peritoneal dialysis in China. Peritoneal Dial Int 2012;32:94-101.

20 Raddatz A, Iseke B, Oleimeulen U, Pommer W, Alscher D, Birk HW, Gloy J, Heuer U, Kitsche B, Pfab T: Assistierte Dialyse - eine Perspektive für Deutschland. Welt der Krankenversicherung 2017;9:210-216.

21 Yu X, Yang X: Peritoneal dialysis in China: meeting the challenge of chronic kidney failure. Am J Kidney Dis 2015;65:147-151.

22 Zhu Y, Huang B, Pan JY, Cheng W, Liu LL, Zhou WD: Assessment of the clinical outcomes of mutual aid mode in elderly patients on peritoneal dialysis. J Nurs Sci 2015;15:32-34.

23 Tao WW, Wang T, Wang L, Wang YZ: Social regression classification of peritoneal dialysis patients. Chinese Journal of Rehabilitation Medicine 2006;9:823-824.

-24 Zhang L, Hawley CM, Johnson DW: Focus on peritoneal dialysis training: working to decrease peritonitis rates. Nephrol Dial Transplant 2015;31:214-222.

-25 Jayanti A, Morris J, Stenvinkel P, Mitra S: Home hemodialysis: Beliefs, attitudes, and practice patterns. Hemodialysis International 2014;18:767-776.

-26 Mehrotra R, Devuyst O, Davies SJ, Johnson DW: The current state of peritoneal dialysis. J Am Soc Nephrol 2016;27:3238-3252.

27 Giuliani A, Karopadi AN, Prieto-Velasco M, Manani SM, Crepaldi C, Ronco C: Worldwide experience with assisted peritoneal dialysis. Perit Dial Int 2017;37:503-508.

28 Covic A, Bammens B, Lobbedez T, Segall L, Heimbürger O, van Biesen W, Fouque D, Vanholder R: Educating end-stage renal disease patients on dialysis modality selection: a clinical advice from the European Best Practice (ERBP) Advisory Board. Nephrol Dial Transpl 2010;3:225-233.

29 Brown E: How to address barriers to peritoneal dialysis in the elderly. Perit Dial Int 2011;31:S83-S85.

30 de Maar JS, de Groot MAJ, Luik PT, Mui KW, Hagen EC: GUIDE, a structured pre-dialysis programme that increase the use of home dialysis. Clin Kidney J 2016:9:826-832. 


\section{Kidney \\ Blood Pressure Research}

31 Liang Y, Wu W: Exploratory analysis of health-related quality of life among the empty-nest elderly in rural China: An empirical study in three economically developed cities in eastern China. Health Qual Life Outcomes 2014;12:59.

-32 Liu LJ, Sun X, Zhang CL, Guo Q: Health-care utilization among empty-nesters in the rural area of a mountainous county in China. Public Health Rep 2007;122:407-413.

33 Yao Q Duddington M: Peritoneal dialysis in China. Perit Dial Int 2014;34:S29-S30.

-34 Li PKT, Chow KM, Van de Luijtgaarden MWM, et al. Changes in the worldwide epidemiology of peritoneal dialysis. Nat Rev Nephrol 2017;13:90.

-35 He M, Zhou J: The Health differences and influencing factors of elderly in urban and rural areas: based on data of CLHLS 2014. Adv Appl Sociol 2018;8:295.

36 Chu LW, Chi I: Nursing homes in China. J Am Med Dir Assoc 2008;9:237-243.

37 Dratwa M: Costs of home assistance for peritoneal dialysis: Results of a European survey. Kidney Int 2008;73:S72-S75.

-38 Laplante S, Krepel H, Simons B, Nijhoff A, van Liere R, Simons M: Offering assisted peritoneal dialysis is a cost-effective alternative to the current care pathway in frail elderly Dutch patients. Int J Healthc Manag 2013;6:27-36.

-39 Iyasere OU, Brown EA, Johansson L, Huson L, Maxwell AP, Farrington K, Davenport A: Quality of life and physical function in older patients on dialysis: A comparison of assisted peritoneal dialysis with hemodialysis. Clin J Am Soc Nephrol 2016;11:423-430.

40 Lobbedez T, Verger C, Ryckelynck JP, Fabre E, Evans D: Is assisted peritoneal dialysis associated with technique survival when competing events are considered? Clin J Soc Nephrol 2012;7:616-618.

41 Harris SA, Lamping DL, Brown EA: Clinical outcomes and quality of life in elderly patients on peritoneal dialysis versus hemodialysis. Perit Dial Int 2001;22:463-470.

$\$ 42$ Morton RL: The views of patients and carers in treatment decision making for chronic kidney disease: a systematic review and thematic synthesis of qualitative studies. BMJ;2018:340:c112.

43 Walker RC, Howard K, Morton RL, Palmer SC, Marshall MR, Tong A: Patient and caregiver values, beliefs and experiences when considering home dialysis as a treatment option: a semi-structured interview study. Nephrol Dial Transpl 2016;31:133-141.

44 Statistisches Bundesamt (Destatis): Bevölkerungsentwicklung bis 2060 (2017). URL: https:// www.destatis.de/DE/Publikationen/Thematisch/Bevoelkerung/VorausberechnungBevoelkerung/ BevoelkerungBundeslaender2060_Aktualisiert_5124207179004.pdf?_blob=publicationFile.

45 MNC: Jahresbericht 2014 zur Qualität der Dialyse (2015). URL: https://www.g-ba.de/downloads/17-983945/2015-07-16_B_QSD-RL_MNC-Jahresbericht-2014_Bericht-MNC.pdf.

46 Statistical Bulletin on National Economic and Social Development in China (2017). URL: http://www.stats. gov.cn/tjsj/zxfb/201802/t20180228_1585631.html.

47 Yi FX, Sun J: Looking at the fertility willingness and population policy from the practice of two children alone, the prospect of China's population in 2015-2080. China Development Observation 2014;12:58-74.

48 Chinese National Renal Data System. URL: http://www.cnrds.net. 